\title{
LOS PRINCIPIOS DE HUMANIDAD DE LAS PENAS, NE BIS IN IDEM, PROPORCIONALIDAD Y EXCLUSIVA PROTECCIÓN DE BIENES JURÍDICOS CONTENIDOS EN LA CONSTITUCIÓN POLÍTICA DE LOS ESTADOS UNIDOS MEXICANOS: ALGUNOS RETOS Y PERSPECTIVAS
}

\author{
The principles of humanity of punishments, ne bis in idem, proportionality and \\ exclusive protection of juridical belongings contained in the Political Constitution \\ of the Unites Mexican States: some challenges and perspectives
}

Leandro Eduardo ASTRAIN BAÑUELOS ${ }^{*}$

Sumario:

I. Introducción II. El primer párrafo del artículo 22 constitucional: la prohibición de penas inhumanas y la exigencia de proporcionalidad en las penas III. Los derechos humanos contenidos en el artículo 23 constitucional: especial referencia al ne bis in ídem IV. Conclusión V. Bibliografía

Resumen: El Sistema penal propio de un Estado Constitucional de Derecho se encuentra construido sobre la base del respeto a los Derechos Humanos de todas las personas. Por ello, el ejercicio de la potestad punitiva estatal está sujeto a límites que no pueden soslayarse y que se encuentran contenidos en la Constitución Política de los Estados Unidos Mexicanos y en instrumentos internacionales signados por México, mismos que son de observancia obligatorio. Del catálogo de principios que se constituyen como la barrera insuperable en la actuación estatal, destacan por su actualidad los de humanidad de las penas, proporcionalidad, ne bis in idem y exclusiva protección de bienes jurídicos, pues el momento histórico de violencia exacerbada por el que está pasando México, ha ocasionado la intensificación del aparato represivo, llegándose incluso a violentar tales principios a través de diversas directrices político criminales.

Palabras clave: Potestad punitiva del Estado, Sistema penal, principio de proporcionalidad, non bis in ídem, bien jurídico, Estado constitucional.

Abstract: The criminal system that belongs to a Constitutional State of Law has been built over the respect for human rights. Therefore, the practice of the punitive power of the State has to be subjected to boundaries that cannot be dismissed because they are established in the Mexican Constitution and in the international treaties signed and ratified by Mexico which have to be observed. There is a decalogue of principles that constituted the insuperable barrier for the state action, among those principles, it is the humanity of punishments, proportionality, ne bis in idem, and the exclusive protection of juridical belongings, because the historical moment of extreme violence in Mexico, has caused the intensification of the repressive system, generating the systematic violation of those principles through criminal public policies.

\footnotetext{
* Doctor en Derecho por la Universidad de Guanajuato. Investigador del Sistema Nacional de Investigadores nivel I. Profesor de Carrera Asociado "C", Tiempo Completo en el Departamento de Derecho de la División de Derecho, Política y Gobierno de la Universidad de Guanajuato. Actualmente, Director de ese Departamento.
} 
Keywords: Punitive power of the State, Criminal system, proportionality principle, non bis in idem, juridical belonging, Constitutional State.

\section{INTRODUCCIÓN}

Siendo el Derecho penal el recurso más drástico con el que cuenta el Estado para resolver los conflictos sociales de mayor trascendencia para la sociedad, resulta indispensable que su uso se encuentre sometido a límites, evitando con ello el abuso de autoridad y el ejercicio arbitrario del poder público. Y es que la potestad punitiva constituye la utilización violencia por parte del Estado que, aunque se encuentra justificada e institucionalizada, no deja de ser violencia.

Por lo anterior, la función del Derecho penal dependerá del tipo de Estado en el que se encuentre inmerso. En uno de corte fascista o totalitario, constituye el brazo armado del Estado, sirve para combatir a los enemigos políticos y para justificar las políticas públicas muchas de las cuales son contrarias a los Derechos Humanos. En cambio, en un Estado Constitucional de Derecho tendrá una función garantista, eminentemente protectora de los bienes jurídicos más preciados de la sociedad para que no sean lesionados ni con los delitos ni con las penas.

Esta protección se lleva a cabo a través de dos vías. Por un lado, criminalizando aquellos comportamientos que se consideran desvalorados al lesionar esos bienes, y por otro, racionalizando la reacción penal a través de la imposición de límites en su ejercicio. No es por ello de extrañar que Franz von Liszt afirmara que el Derecho penal es la barrera infranqueable de la política criminal ${ }^{1}$.

Tales límites se expresan a través de principios que dan soporte y legitimidad al ius puniendi, y que dada su importancia se encuentran contenidos en las leyes fundamentales de los Estados. En la medida en que esos principios sean respetados por todos los operadores del sistema penal, el derecho punitivo cumple con su función garantizadora. Por el contrario, cada que son violados (y fomentada o tolerada esa violación) hay ruptura en el sistema y el Derecho penal comienza a transitar hacia uno de corte autoritario ${ }^{2}$. Como lo señala Sergio García Ramírez, sigue siendo el Derecho penal, así sustantivo como adjetivo y ejecutivo, por encima de cualesquiera otros órdenes jurídicos, el escenario crítico de los derechos humanos ${ }^{3}$.

Así las cosas, en la Constitución Política de los Estados Unidos Mexicanos (en adelante CPEUM) encontramos un programa de naturaleza penal por virtud del cual se reconocen una serie de prerrogativas para los destinatarios del sistema penal, principalmente para imputados, aunque ahora también para las víctimas. Este programa penal constitucional se expresa a través de un conjunto de principios que también son contemplados y ampliados en instrumentos internaciones. Por ello, tal y como lo ha señalado la Suprema Corte de Justicia de la Nación, en

\footnotetext{
${ }^{1}$ Citado por Roxin, Claus (1997), Derecho Penal. Parte General Tomo I Fundamentos. La estructura de la teoría del Delito, traducción de la segunda edición alemana de Diego-Manuel Luzón Peña, Miguel Díaz y García Conlledo y Javier de Vicente Remesal, Madrid, Editorial Thomson Civitas, p. 223.

${ }^{2}$ Como nos recuerda Zaffaroni, Eugenio Raúl (2006), El enemigo en el Derecho penal, Buenos Aires, Ediar, pp. 165-166, Los estados de derecho no son otra cosa que la contención de los estados policía, contención trabajosamente conseguida como resultado de la experiencia acumulada a lo largo de luchas seculares contra el poder absoluto (...) Debido a esto, existe una continua dialéctica en el estado de derecho real, concreto e histórico, entre éste y el estado policía. El estado policía nunca cesa de pulsionar por perforar y estallar las vallas que le coloca el estado de derecho.

${ }^{3}$ García Ramírez, Sergio (1976), Los derechos humanos y el Derecho penal, México, Secretaría de Educación Pública, p. 13.
} 
la tesis cuyo rubro es DERECHOS HUMANOS CONTENIDOS EN LA CONSTITUCIÓN Y EN LOS TRATADOS INTERNACIONALES. CONSTITUYEN EL PARÁMETRO DE CONTROL DE REGULARIDAD CONSTITUCIONAL, PERO CUANDO EN LA CONSTITUCIÓN HAYA UNA RESTRICCIÓN EXPRESA AL EJERCICIO DE AQUÉLLOS, SE DEBE ESTAR A LO QUE ESTABLECE EL TEXTO CONSTITUCIONAL, el parámetro de control de regularidad constitucional está conformado por los derechos humanos tanto de fuente nacional (los contenidos en la constitución) como internacional (los previstos en los tratados internacionales independientemente de su naturaleza, siempre y cuando sean de observancia obligatoria en México y reconozcan prerrogativas fundamentales para las personas) ${ }^{4}$.

Dentro de los derechos antes referidos, en el presente artículo nos referiremos a los contenidos en los artículos 22 y 23 constitucionales y que hacen referencia a los principios de prohibición de penas inhumanas (una vertiente del principio de dignidad humana), de proporcionalidad y exclusiva protección de bienes jurídicos y al llamado ne bis in ídem.

\section{El primer párrafo del artículo 22 constitucional: la prohibición de penas inhumanas y la exigencia de proporcionalidad en las penas}

Señala el primer párrafo del artículo 22 de la CPEUM lo siguiente: Quedan prohibidas las penas de muerte, de mutilación, de infamia, la marca, los azotes, los palos, el tormento de cualquier especie, la multa excesiva, la confiscación de bienes y cualesquiera otras penas inusitadas y trascendentales. Toda pena deberá ser proporcional al delito que sancione y al bien jurídico afectado.

La primera parte de este párrafo prohíbe la imposición de determinadas penas corporales y dos de carácter pecuniario, que han quedado proscritas del orden jurídico mexicano. De hecho, ninguno de los códigos penales de nuestro país, tanto a nivel federal como local llegó a contemplarlas, salvo la pena de muerte que sí fue prevista por algunos de ellos. La prohibición de estas penas se justifica en virtud de que constituyen una violación a la dignidad de la persona humana y porque no abonan al fin constitucional de la pena previsto en el artículo 18: la reinserción social del delincuente.

El Derecho penal primitivo se caracterizaba por su irracionalidad y por la dureza de las sanciones, que eran excesivas. Incluso, en los cuerpos normativos de las sociedades antiguas la parte penal era de mucho mayor proporción que las de la parte civil. Henry Maine nos dice que cuanto más arcaico sea el código, más completa y minuciosa es su legislación penal. Este fenómeno ha sido observado a menudo y se ha explicado, en buena medida con razón, en términos de la violencia habitual en las comunidades que pusieron por escrito por primera vez sus leyes. Estos cuerpos normativos contenían sanciones que buscaban el sufrimiento del delincuente y la disuasión del delito a través de penas ejemplares que perduraran en el infractor y por ende en la consciencia colectiva, siendo las principales las corporales y la de muerte, pues habrá que recordar que la pena de prisión no se encontraba prevista en esos cuerpos normativos, salvo muy excepcionalmente o como un medio para asegurar el procesamiento del reo, es decir como una mediad cautelar. Es hasta mediados del siglo XVI, que comienzan a construirse estableci-

\footnotetext{
${ }^{4}$ Cfr. Tesis: P./J. 20/2014 (10a.), Semanario Judicial de la Federación y su gaceta, Décima Época, Libro 5, Tomo I, abril de 2014, p. 202

5 Maine, Henry (2001), El Derecho antiguo, traducción de Pastora Rodríguez Aviñoá, México, Editorial Campo Raso, pp. 317-318.
} 
mientos ex profeso para la compurgación de penas de prisión y con ello suprimir las penas de corporales y de muerte ${ }^{6}$.

Una de las principales preocupaciones del Estado mexicano al obtener su independencia de la Corona Española fue la de implementar un proceso penal realmente democrático por virtud del cual se proscribiera el sistema penal de corte inquisitorial heredado de la época virreinal. Sin embargo, no es hasta la Constitución Federal de los Estados Unidos Mexicanos sancionada y jurada por el congreso general constituyente el 5 de febrero de 1857 que por primera vez se reconocen en México a nivel constitucional los derechos humanos, razón por la cual su artículo 22 prohibió la imposición de penas corporales en los términos siguientes: Quedan para siempre prohibidas las penas de mutilación y de infamia, la marca, los azotes, los palos, el tormento de cualquier especie, la multa excesiva, la confiscación de bienes y cualquiera otras penas inusitadas o trascendentales.

Por su parte, el artículo 23 del referido ordenamiento constitucional señalaba que:

Para la abolición de la pena de muerte, queda a cargo del poder administrativo es establecer, a la mayor brevedad el régimen penitenciario. Entre tanto, queda abolida para los delitos políticos y no podrá extenderse a otros casos más que al traidor a la patria en guerra extranjera, al salteador de caminos, al incendiario, al parricida, al homicida con alevosía, premeditación o ventaja, a los delitos graves del orden militar y a los de piratería que definiera la ley.

Estas disposiciones son retomadas de forma casi similar en los párrafos primero y tercero de la redacción original de la Constitución mexicana de 1917, quedando en los términos arriba referidos en virtud de una serie de reformas constitucionales de las que hablaremos líneas más adelante.

La mutilación consistía en cortar alguna parte del cuerpo vivo del sentenciado (como por ejemplo, la castración de los delincuentes sexuales en la Alemania nazi o el cortar las manos a los que comenten un robo, sanción que actualmente se aplica en Irán y Arabia Saudita). La infamia era una institución del derecho romano, actualmente en desuso, consistente en una especie de degradación civil que tenía diversas causas, varias de ellas relacionadas con la condena por la comisión de crímenes públicos y algunos delitos privados, cuyos efectos eran la pérdida de varios derechos como los honores o el sufragio ${ }^{7}$. La marca era la imposición de una señal en el cuerpo (como en el antiguo derecho penal español que se sancionaba al polígamo marcándole una Q con hierro candente en la frente). A través de los azotes se causaba dolor y sufrimiento a la persona con un instrumento formado por cuerdas anudadas (siendo paradigmática la imposición de esta pena a Jesús por parte de Poncio Pilatos durante el proceso de Cristo). Los palos era una forma de ejecutar la pena capital cuya característica era la utilización palos o garrotes (pena que era practicada por los aztecas). El tormento es una práctica consistente en ocasionar dolores o sufrimientos graves a las personas con el propósito de obtener información de ellas o que hagan o dejen de hacer algo, mismo que cuando es realizado por servidores públicos en ejercicio de sus funciones se le denomina jurídicamente con el término tortura. La multa excesiva es una pena pecuniaria consistente en el pago de una determinada suma de dinero que resulta desproporcionada en relación con el hecho cometido y con la capacidad económica del infractor. La otra pena pecuniaria prohibida por esta misma disposición jurídica es la confisca-

\footnotetext{
${ }^{6}$ Véase Rodríguez Manzanera, Luis (2015), Penología, séptima edición, México, Editorial Porrúa, pp. 209 -215.

7 Véase SAvigny, Friedrich Karl von (2004), Sistema del Derecho romano actual, edición facsimilar de la 1879, México, Suprema Corte de Justicia de la Nación, Tomo II, pp. 20-56. 
ción, por medio de la cual se priva de la totalidad o de algunos de los bienes del infractor que no tienen relación con el hecho punible.

Por penas inusitadas debemos entender aquellas que no se encuentren previstas en el catálogo anterior y que de igual forma resultan crueles e inhumanas. Las penas trascendentales son aquellas que, como su nombre lo indica, trascienden de la persona del inculpado, es decir, las que se imponen a sus familiares o a terceros. En este sentido, en la tesis cuyo rubro es PENAS INUSITADAS Y TRASCENDENTALES, QUE SE ENTIENDE POR, la Primera Sala de la Suprema Corte de Justicia de la Nación ha señalado que por penas inusitadas no se debe entender su sentido gramatical, esto es, lo no usado, pues ello impediría el progreso de la ciencia penal, ya que cualquier tipo de pena innovadora podría considerarse inusitada. Para la referida sala, por penas inusitadas debemos entender aquellas penas que han sido abolidas por inhumanas, crueles, infamantes o excesivas, así como las que no cumplen con el fines que persigue la penalidad, o aquellas que sin haber existido produzcan los mismos efectos. Por otro lado, son penas trascendentales las que cuyos efectos inciden más allá del propio condenado, particularmente en sus parientes ${ }^{8}$.

No obstante que efectivamente dichas penas no se encuentran contempladas en ninguno de los ordenamientos penales vigentes en México, y por ende no existe la posibilidad de una condena que efectivamente las imponga, la realidad nos demuestra que varios de los comportamientos prohibidos por esta disposición normativa, constituyen prácticas cotidianas en el ejercicio clandestino del ius puniendi. En efecto, la tortura y otros tratos crueles y degradantes son conductas que no han sido del todo erradicadas en nuestro país. Por el contrario, en el marco de la guerra contra el narcotráfico declarada en el sexenio del presidente Calderón y continuada en el del presidente Peña, las denuncias por tortura y malos tratos se han disparado en los últimos doce años. En el documento titulado La tortura en México: una mirada desde los organismos del Sistema de Naciones Unidas, publicado conjuntamente por la Comisión Nacional de Derechos Humanos (CNDH) y la Oficina en México del Alto Comisionado de Naciones Unidas para los Derechos Humanos, se afirma que las denuncias contra estas prácticas aumentaron a partir del año de 2007. La CNDH recibió 11608 quejas por tortura entre 2006 y abril de 2014; la Comisión de Derechos Humanos del Distrito Federal atendió 386 quejas de esta naturaleza entre 2011 y febrero de 2014; por su parte, la sociedad civil tiene más de 500 casos documentados entre 2006 y 2014. A pesar de ello, el documento revela que solo cinco sentencias condenatorias fueron emitidas a nivel federal durante el periodo comprendido entre los años de 2005-2013, lo que refleja la gran impunidad que se vive en este tema9 ${ }^{\text {. }}$

Frente a los problemas que representa la práctica ilícita de la tortura y otros tratos crueles, inhumanos y degradantes, existe tendencias por regularizar su uso como un mecanismo lícito para obtener información en la investigación de delitos de alto impacto, particularmente en los casos de terrorismo o secuestro ${ }^{10}$, lo que es sumamente preocupante, pues ello representa una clara regresión a las épocas primitivas del Derecho penal. En un informe de 1989, la Co-

\footnotetext{
${ }^{8}$ Cfr. Tesis: Sin número, Semanario Judicial de la Federación y su gaceta, Quinta Época, Tomo XL, p. 2398.

${ }^{9}$ Cfr. La tortura en México: una mirada desde los organismos del Sistema de Naciones Unidas, México, Comisión Nacional de Derechos Humanos, Oficina en México del Alto Comisionado de Naciones Unidas para los Derechos Humanos, 2015, [en línea], disponible en: http://appweb.cndh.org.mx/biblioteca/archivos/pdfs/lib_TorturaMexicoUnaMirada.pdf, [consultada el 15 de mayo de 2018].

${ }^{10}$ En el caso de secuestro, es paradigmático el caso Daschner ocurrido en Alemania en el año 2002 y que generó una amplia discusión en torno a los efectos procesales y extraprocesales de la utilización de la tortura como técnica de investigación del delito. Al respecto, véase, Roxın, Claus (2005), ¿Puede llegar a justificarse la tortura?, México, Instituto Nacional de Ciencias Penales, colección Conferencias Magistrales, número 12.
} 
misión de Análisis en los Métodos de Investigación del Servicio de Seguridad General sobre la Actividad Terrorista Hostil de Israel, señaló que el interrogatorio de sospechosos terroristas es imposible sin el uso de medios de coacción para superar su obstinada voluntad de no revelar información y para superar el miedo de la persona bajo interrogatorio de que el daño provendrá de su propia organización, si revela la información $n^{11}$. A principios del año 2017, el presidente de Estados Unidos de América, Donald Trump, declaró en una entrevista que las prácticas de interrogatorio utilizadas en el pasado en la lucha contra el terrorismo y consideradas como tortura (por ejemplo, el ahogamiento simulado), podían resultar eficaces y por tanto podría volver a utilizarlas, no obstante que dichas prácticas habían cesado con el mandato del presidente Barack Obama ${ }^{12}$.

En relación con las penas trascendentales, en México no pocos ordenamientos punitivos contemplan la pena de reparación del daño exigible a terceros, que aunque no sean considerados penalmente responsables, sí se les condena a la reparación del daño a favor de la víctima. Casos como el del dueño de una negociación que es obligado a dicho pago por el hecho punible cometido por uno de sus empleados en el ejercicio de sus funciones. En estos supuestos estimamos que tales normas transgreden este precepto constitucional al tratarse de una pena trascendental y por ende resultan inconstitucionales.

Del catálogo mencionado como penas prohibidas por el primer párrafo del artículo 22 constitucional, la pena de muerte fue la última que tuvo vigencia en México todavía a principios del presente siglo. El Código de Justicia Militar la contemplaba como sanción para diversos tipos penales, quedando derogada dicha pena en el 2005, año en el que también fue modificado el primer párrafo del artículo en estudio para prohibir también la pena de muerte. Y aunque se encontraba legalmente prevista en el Código de Justicia Militar y la redacción original del artículo 22 constitucional no la prohibía, la realidad es que su ejecución fue muy limitada, inclusive, la última vez que fue aplicada en México fue en el año de 1961.

La última parte del primer párrafo del artículo en estudio señala que Toda pena deberá ser proporcional al delito que sancione y al bien jurídico afectado. Esta disposición constituye una adición producto de la reforma constitucional que en materia penal fuera publicada en el Diario Oficial de la Federación el 18 de junio de 2008 y por virtud de ella se elevó a rango constitucional la teoría del bien jurídico en materia penal ${ }^{13}$.

En esta tesitura, adquiere importancia el proceso de selección de bienes jurídicos que requieren de protección penal. Así, sólo será justificada la intervención penal frente a comportamientos que lesionan o ponen en peligro a un bien considero de especial importancia y que resulta indispensable para garantizar la coexistencia pacífica de los individuos en la sociedad.

Esta circunstancia también es evidenciada en el Código Nacional de Procedimientos Penales, al establecer en el último párrafo del Artículo 487 que La sola causación del resultado no podrá

\footnotetext{
${ }^{11}$ Амвоs, Kai (2009), Terrorismo, tortura y Derecho penal. Respuestas en situaciones de emergencia, Barcelona, Atelier, colección Justicia penal, número 20, p. 22.

${ }^{12}$ Tomado de la nota Trump apoya la tortura en los interrogatorios como método efectivo para combatir el terrorismo, El Mundo, 27 de enero de 2017, [en línea], disponible en: http://www.elmundo.es/internacional/2017/01/26/5 8896262e5fdeaad368b465f.html, [consultada el 15 de mayo de 2018].

${ }^{13}$ No obstante que la función protectora de bienes jurídicos del Derecho penal constituye una premisa casi irrefutable en la Dogmática penal, la teoría del bien jurídico se encuentra seriamente cuestionada en Alemania, a partir de una resolución del Tribunal Constitucional alemán que se aparta de ella para determinar la legitimación de la criminalización del incesto. Sobre esta discusión véase BURCHARD, Christoph (2016), "La Constitucionalización de los fundamentos del Derecho Penal alemán", en Aмвоs, Kai et al (2006 editores), Desarrollos actuales de las ciencias criminales en Alemania, Göttingen, Göttingen University Press, pp. 31-51.
} 
fundamentar, por sí sola, la responsabilidad penal. Por su parte los tipos penales estarán limitados a la exclusiva protección de los bienes jurídicos necesarios para la adecuada convivencia social.

Llama la atención que la redacción de esta última parte del artículo 22 solamente hable de afectación al bien jurídico, lo que desde nuestra perspectiva implica la imposibilidad de sancionar la tentativa, pues ello representaría un acto inconstitucional. Esto es así, porque en el momento en que entró en vigor esta reforma constitucional, los códigos penales que sancionan la tentativa se convirtieron en inconstitucionales, dado que ahora la exigencia constitucional es que la pena deba ser proporcional a la afectación al bien jurídico y si no existe esa afectación, como en los casos de tentativa (pues ella representa solamente la puesta en peligro a dicho bien), no es procedente la imposición de una pena.

Así las cosas, esta adición al artículo 22 constitucional se convierte en una directriz político criminal que obliga a todos los operadores del sistema penal a intervenir, en sus respectivos ámbitos competenciales, una vez que se requiere una efectiva protección penal de un bien jurídico (mandato dirigido al legislador penal) y siempre que se haya verificado una lesión a dicho bien jurídico (mandato dirigido tanto al persecutor como al juzgador penal).

Por su parte, la proporcionalidad en materia penal se refiere a la necesaria relación que debe existir entre la gravedad del hecho realizado por el autor con la gravedad de la pena impuesta por el Estado. De tal suerte que impera en este principio la idea de justicia que subyace en todo ordenamiento jurídico. No obstante lo anterior, en la actualidad este es uno de los principios más violados tanto por los operadores del sistema penal en sede legislativa como en sede judicial. Cada vez son más los tipos penales que contemplan penas privativas de la libertad de larga duración, en muchos de los casos a límites groseros, como en el supuesto previsto en la Ley General para prevenir y sancionar los delitos en materia de secuestro, que prevé una pena de hasta 140 años de prisión en caso de que la víctima de secuestro sea privada de la vida. Y de igual forma este endurecimiento de la pena se aprecia en la práctica cotidiana de la función jurisdiccional en donde se imponen penas de acuerdo a la norma pero en contra del mandato constitucional de proporcionalidad. Sin lugar a dudas, estas directrices político criminales representan verdaderos retos para la el derecho penal de corte garantista.

\section{Los derechos humanos contenidos en el artículo 23 constitucional: especial referencia al ne bis in idem}

Dispone el artículo 23 de nuestra Carta Magna que Ningún juicio criminal deberá tener más de tres instancias. Nadie puede ser juzgado dos veces por el mismo delito, ya sea que en el juicio se le absuelva o se le condene. Queda prohibida la práctica de absolver de la instancia.

Este artículo reconoce tres derechos humanos de naturaleza adjetiva para los justiciables: la prohibición de contemplar más de tres instancias en los procedimientos penales; el non bis in 
ídem o ne bis in ídem (que en una de sus vertientes puede concebirse como un derecho de naturaleza sustantiva) y; la prohibición de absolver la instancia ${ }^{14}$.

La primera parte del artículo contiene el derecho de todo justiciable a no ser procesado penalmente en más de tres instancias, lo que se traduce en una prohibición al legislador penal para contemplar una cuarta instancia en el ordenamiento procesal penal.

La instancia se refiere al conjunto de actos procesales que concluyen con la resolución del litigio sometido a la consideración del juzgador. Por regla general, los juicios penales tienen dos instancias. En la primera, conformada por los actos propios de la Audiencia de Juicio Oral prevista en el Código Nacional de Procedimientos Penales, las partes exponen ante el tribunal de enjuiciamiento su pretensión y defensa (alegatos de apertura), fijándose con ello la litis, se desahogan las pruebas admitidas a las partes, se rinden alegatos de clausura y se dicta la sentencia definitiva, es decir, aquella que resuelve el fondo del asunto. En la segunda instancia, el tribunal de alzada revisa la sentencia de primera instancia a partir de la interposición del recurso de apelación por cualquiera de las partes o por ambas, en el que se expresarán los agravios que causa la resolución recurrida. En el ámbito jurídico penal, esta segunda instancia es un derecho humano de los inculpados, en términos de lo dispuesto por la Convención Americana sobre Derechos Humanos que en su artículo 8.2 inciso h señala que toda persona inculpada de delito tiene derecho a recurrir del fallo ante juez o tribunal superior ${ }^{15}$.

Por otra parte, existe una aceptación mayoritaria por parte de la doctrina mexicana en considerar que el juicio de amparo directo promovido en contra de la sentencia dictada en segunda instancia no constituye una nueva instancia, pues el amparo es un juicio autónomo en el que la litis es diferente a la planteada en el proceso penal, ya que en el juicio constitucional se analiza si el acto de la autoridad responsable, en este caso la sentencia de la apelación, es acorde al parámetro de control de regularidad constitucional y no se determina de manera directa si el sujeto es responsable o no penalmente. Al respecto, nos dice Humberto Enrique Ruiz Torres que el amparo directo

es un proceso jurisdiccional impugnativo, ordinariamente de una sola instancia y extraordinariamente de doble instancia, que tiene por objeto anular, en los casos concretos, las sentencias definitivas, laudos o resoluciones que pongan fin al juicio sin resolver la controversia de

\footnotetext{
${ }^{14} \mathrm{Al}$ respecto, véase Zamora-Pierce, Jesús (2003), Garantías y proceso penal, doceava edición, México, Editorial Porrúa, 2003, pp. 355-404 y; BURgOA Orinuela, Ignacio (1999), Las garantías individuales, trigésimo primera edición, México, Editorial Porrúa, pp. 665-669.

${ }^{15}$ Sobre la criterios de la Corte Interamericana de Derechos Humanos en relación al contenido y alcance del derecho a recurrir el fallo ante un juez o tribunal superior en el proceso penal previsto en este artículo de la Convención Americana sobre Derechos Humanos, véase SteIner, Christian y URIBE, Patricia (2015 coord.), Convención Americana sobre Derechos Humanos comentada, México, Suprema Corte de Justicia de la Nación, Konrad Adenauer Stiftung, pp. 243-245. Críticos con estos criterios, DuCE, Mauricio y RiEgo, Cristian (2009), Proceso penal, Santiago de Chile, Editorial Jurídica de las Américas, pp. 503-532.
} 
fondo (lo mismo que las leyes que se hayan aplicado en ellos), cuando han sido emitidas en perjuicio de los gobernados ${ }^{16}$.

Por ello, si fuera impugnada la sentencia dictada en el amparo directo a través del recurso de Revisión previsto por el artículo 81 fracción II de la Ley de Amparo no podríamos considerarla propiamente una cuarta instancia.

Caso diverso lo constituye el procedimiento de Reconocimiento de Inocencia del sentenciado previsto en los artículos 486, 488, 489 y 490 del Código Nacional de Procedimientos Penales, institución jurídica que representa una excepción a la cosa juzgada en materia penal, y que procede en los casos en que una vez que la sentencia ejecutoria ha causado estado, sobreviene una prueba que evidencia sin lugar a dudas la inocencia del condenado, por lo que una vez desahogado el procedimiento respectivo se emitiría una nueva resolución, lo que sería propiamente un juicio en una nueva instancia. Sin embargo, este reconocimiento no puede considerarse violatorio de este derecho, pues sería una tercera instancia y además se realiza en beneficio del gobernado, pues su situación jurídica no se podría ver más afectada, sino eventualmente beneficiada si es procedente dicho reconocimiento. Como lo reconoce Jorge A. Silva Silva, se trata sólo de favorecer al penalmente condenado y no de perjudicarlo, esto es, no se trata de revisar la sentencia con la finalidad de condenar al injustamente absuelto, circunstancia que, a decir de Prieto-Castro y Alcalá-Zamora, ocurre en la legislación alemana y llegó a darse en México ${ }^{17}$.

El segundo derecho humano contenido en el artículo en estudio es el llamado principio non bis in ídem o ne bis in ídem que el constituyente redacta en los siguientes términos: Nadie puede ser juzgado dos veces por el mismo delito, ya sea que en el juicio se le absuelva o se le condene. Este derecho contempla una doble vertiente. La primera de ellas se desprende su interpretación literal y por virtud de la cual se prohíbe enjuiciar penalmente en más de una ocasión a una persona por los mismos hechos. Con esta prerrogativa se pretende otorgar seguridad jurídica a los inculpados para que una vez que se cuenta con una sentencia ejecutoria, independientemente de su sentido, el sujeto no sea sometido de nueva cuenta a un proceso penal por el hecho o los hechos que ya fueron juzgados.

Diversas problemáticas se presentan al materializar este derecho humano. La primera de ellas consiste en determinar en qué momento se considera que una persona ya ha sido juzgada penalmente. Existe un criterio reiterado por parte de la mayoría de los tribunales federales en México, en el sentido de que tal situación se presenta una vez que existe sentencia definitiva que ha causado estado y por ende resulta inimpugnable. Así, tal derecho se vería conculcado cuando el sujeto fuera sometido a un nuevo proceso penal, no obstante que se actualizaría a su favor la excepción de cosa juzgada ${ }^{18}$. Para que dicha excepción sea procedente en el ámbito penal se requiere un criterio diferente al tradicionalmente planteado por los procesalistas civiles (identidad de acciones, partes y objeto), pues en este ámbito habrá cosa juzgada cuando en el nuevo proceso penal se trate del mismo inculpado y del mismo hecho punible objeto del pro-

\footnotetext{
${ }^{16}$ Ruiz Torres, Humberto Enrique (2007), Curso general de amparo, México, Oxford University Press, colección Textos jurídicos universitarios, p. 539.

${ }^{17}$ Silva Silva, Jorge A. (1995), Derecho procesal penal, segunda edición, México, Oxford University Press, colección Textos jurídicos universitarios, p. 462.

${ }^{18}$ Al respecto véase Valadez Díaz, Manuel et al (2011), Diccionario práctico del juicio oral, México, Ubijus, p. 140.
} 
ceso anterior (aunque la Constitución utiliza la expresión delito, se refiere al hecho atribuido independientemente de la calificación jurídica que se le dé al mismo).

Por otra parte, la existencia simultánea de dos procesos penales con identidad de inculpado y de hecho punible atribuido da lugar a la procedencia de la excepción de Litispendencia ${ }^{19}$ en la segunda causa penal y por ende a su sobreseimiento.

El Código Nacional de Procedimientos Penales no regula expresamente el momento procesal para la oposición de las excepciones antes planteadas, no obstante que los códigos procesales penales de los estados que contemplaban el sistema acusatorio adversarial antes de la entrada en vigor del ordenamiento procesal penal nacional, si lo preveían: por regla general se hacían valer una vez que se notificaba la acusación al imputado y daba contestación a dicho escrito ante el juez de control o garantía durante la etapa intermedia, previéndose la posibilidad de también hacerlas valer ante el Tribunal de enjuiciamiento una vez que se notificaba el auto de apertura de juicio oral al propio acusado. Por nuestra parte, consideramos que en virtud de que el Código Nacional no prevé expresamente el trámite para la interposición de estas excepciones, y al ser ambas de previo y especial pronunciamiento, se debe realizar por parte del imputado o su defensa, vía incidental y una vez que se le ha formulado imputación respecto de los hechos materia de otro juicio ya concluido o en proceso, pues resultaría innecesario continuar con la vinculación a proceso y la investigación complementaria de resultar procedente cualquiera de las excepciones planteadas. De continuar el proceso penal siendo cualquiera de estas excepciones procedente, estaríamos en usando innecesariamente recursos humanos y materiales.

Otra cuestión que se presenta es la relativa al caso de que la primera sentencia fuera dictada por un juez incompetente. En este supuesto nosotros consideramos que el derecho concedido al inculpado no es sólo formal, sino también material, de tal suerte que constituiría un fraude al espíritu del constituyente estimar que al haberse realizado ante un juez incompetente es factible someter a un nuevo proceso penal al inculpado, cuando materialmente ya fue sometido a un proceso con todo el desgaste físico y emocional que ello representa. Por ello no compartimos los diversos criterios de jurisprudencia que estiman que el principio ne bis in ídem no se violenta si se lleva a cabo un nuevo proceso ante un juez competente cuando el primero se realizó ante uno que no lo era ${ }^{20}$.

En cuanto al tratamiento del delito continuado, se pueden presentar situaciones dignas de ser analizadas. Esta forma de realización del tipo se actualiza cuando varias conductas provocan diversos resultados típicos, tratándose de la misma víctima y violándose el mismo precepto legal. En este supuesto estamos en presencia de un concurso real de delitos, al que el legislador da un tratamiento específico en virtud de que, de aplicarse las punibilidades previstas para este tipo de concursos, podría implicar la imposición de una pena elevada y desproporcionada ${ }^{21}$. De ahí que la solución político criminal sea la de crear una figura diversa que expresamente regule esa situación, evitando con ello el exceso en el ejercicio del ius puniendi. Así, pudiera presentarse el caso que algunas de las conductas del delito continuado no fueran objeto del primer proceso penal, razón por la cual podría iniciarse uno nuevo cuyo objeto serían esos comportamientos. Por nuestra parte creemos que dicho proceso vulneraría el principio en estudio puesto que el delito continuado se desvalora íntegramente incluyendo todas las conductas que expresamente

\footnotetext{
${ }^{19}$ Ídem.

${ }^{20}$ Por todas, véase la tesis cuyo rubro es NON BIS IN IDEM, CASOS EN QUE NO OPERA de la Primera Sala de la Suprema Corte de Justicia de la Nación. Tesis: sin número, Semanario Judicial de la Federación y su gaceta, Sexta Época, Volumen LXIII, segunda parte, 26 de septiembre de 1962, p. 50.

${ }^{21}$ Al respecto, véase Castellanos Tena, Fernando (2008), Lineamientos elementales de Derecho penal, cuadragésima edición actualizada por Horacio Sanchez Sodi, México, Editorial Porrúa, pp. 138-139. 
no se señalaran -inclusive en no pocas ocasiones sería materialmente imposible acreditar todas y cada una de ellas. Sin embargo, consideramos que si las conductas fueran posteriores al dictado de la vinculación a proceso, ello si daría lugar al inicio de un nuevo proceso penal pues tales hechos no fueron materia del delito continuado objeto del primer proceso penal.

Un caso particularmente conflictivo es la reposición del procedimiento previsto en el trámite del recurso de apelación contenido en el Código Nacional de Procedimientos Penales así como el otorgamiento del amparo para efectos de reposición del procedimiento por violaciones procesales. En ambos supuestos es claro que no existe cosa juzgada pues la sentencia definitiva no ha causado estado. Sin embargo, tales reposiciones de procedimiento implican la realización material de un nuevo juicio y por ende una alerta al principio que analizamos. Considero que si existen violaciones graves al debido proceso imputadas a órganos del Estado, más que reponer el procedimiento, lo procedente tendría que ser la absolución del acusado. Con ello se desincentivaría las violaciones graves al debido proceso.

La otra vertiente del derecho humano en estudio va relacionado con otro de los fines del ne bis in ídem. Como lo señalamos, lo que se pretende con este derecho es otorgar seguridad jurídica al justiciable en materia penal, pero el fin último de este principio es evitar que se sancione en más de una ocasión por el mismo hecho. Por ello, existe también un amplio consenso en la doctrina penal en entender que este derecho humano implica el no ser juzgado dos o más veces por el mismo hecho punible, pero tampoco a ser sancionado en más de una ocasión por el mismo hecho. Las consecuencias de esta decisión político criminal tiene alto impacto en el ejercicio de la criminalización tanto en sede judicial, legislativa y ministerial. En no pocas ocasiones un mismo comportamiento puede encuadrar en dos o más tipos penales, que resultan incompatibles, razón por la cual la dogmática penal ha desarrollado la institución denominada Concurso aparente de normas ${ }^{22}$, la cual, a través de diversos principios como el de especialidad, subsidiariedad, absorción o alternatividad, determina cuál de las normas concurrentes resulta aplicable al caso concreto, evitando con ello la imposición de múltiples sanciones que vulneraría el ne bis in ídem.

Por estas mismas razones nos mostramos críticos de las normas penales que en forma de agravantes sancionan la reincidencia o la habitualidad, pues ello implica aumentar la pena al infractor por la realización de comportamientos previos que ya han sido sancionados ${ }^{23}$.

Una situación que requiere un análisis profundo lo constituyen los casos en que un mismo comportamiento resulta desvalorado y por tanto sancionado por diversas ramas del orden jurídico. Ejemplo de ello lo encontramos en el Código Fiscal de la Federación, en donde algunas conductas configuran al mismo tiempo una infracción administrativa y un ilícito penal con las sanciones respectivas en cada ámbito. El criterio recurrente en la jurisprudencia nacional es considerar que la imposición de las correspondientes sanciones no vulnera el derecho humano en estudio.

Más aún, con la reforma constitucional publicada en el Diario Oficial de la Federación el 27 de mayo de 2015 y por virtud del cual se establece el Sistema Nacional Anticorrupción, es posible considerar a un mismo hecho como delito y como infracción administrativa, imponiéndose al infractor las sanciones de naturaleza civil y penal de forma autónoma y sin que ello violente

\footnotetext{
${ }^{22}$ En México, existen dos importantes monografías que desarrollan el tema: PAvón VAsconcelos, Francisco (2008), Concurso aparente de normas, séptima edición, México, Editorial Porrúa; y Nuñez Ávalos, Daniel (2008), El concurso aparente de normas penales, México, Editorial Porrúa.

${ }^{23}$ En este sentido, véase Zaffaroni, Raúl et al (2005), Derecho penal. Parte general, segunda edición, México, Editorial Porrúa, pp. 1057-1063.
} 
el principio ne bis in ídem en atención a que son de diversa naturaleza, según lo establece el artículo 109 fracción III de la propia CPEUM.

Por nuestra parte, tampoco compartimos estas consideraciones, pues además de constituir una doble sanción por los mismos hechos, también viola la ultima ratio del Derecho Penal. Si otra rama del derecho ha entrado en acción ante una problemática social, resolviéndola a través de una sanción, la intervención penal resulta innecesaria y por ende ilegítima.

Finalmente, el último derecho humano contenido en la disposición constitucional en comento es la prohibición de absolver de la instancia, práctica desterrada en nuestro país pero que en la antigüedad era recurrente. Consistía en la no resolución del caso sometido a la consideración del órgano jurisdiccional en atención a que no existían elementos suficientes para fundamentar la condena, pero tampoco para la absolución, razón por la que no se decidía respecto de la responsabilidad penal, permitiendo la apertura de una nueva instancia en la que con libertad de jurisdicción se podía resolver sobre la inocencia o culpabilidad del procesado, lo que violentaba la seguridad jurídica.

\section{Conclusión}

Los límites a la potestad punitiva del Estado representan principios que le dan soporte y legitimidad al Derecho penal en un Estado Constitucional. A su vez, esos principios constituyen derechos humanos reconocidos a los destinatarios de las normas penales, razón por la cual bajo ninguna circunstancia deben ser violados, pues ello representa una negación al régimen democrático que caracteriza al Estado de constitucional de Derecho.

Dentro de estos límites, destacan por su importancia y actualidad, los principios de humanidad de las penas, proporcionalidad de las mismas, ne bis in ídem y exclusiva protección de bienes jurídicos. Y es que las actuales directrices político criminales en México evidencian una clara negación de estos principios y por ende un llamado de alerta al Derecho penal garantista.

\section{Bibliografía}

Амвоs, Kai (2009), Terrorismo, tortura y Derecho penal. Respuestas en situaciones de emergencia, Barcelona, Atelier, colección Justicia penal, número 20.

Burchard, Christoph (2016), "La Constitucionalización de los fundamentos del Derecho Penal alemán”, en AMBOS, Kai et al (editores), Desarrollos actuales de las ciencias criminales en Alemania, Göttingen, Göttingen University Press.

Burgoa Orihuela, Ignacio (1999), Las garantías individuales, trigésimo primera edición, México, Editorial Porrúa.

Castellanos Tena, Fernando (2008), Lineamientos elementales de Derecho penal, cuadragésima edición actualizada por Horacio SANCHEz Sodi, México, Editorial Porrúa.

Duce, Mauricio y Riego, Cristian (2009), Proceso penal, Santiago de Chile, Editorial Jurídica de las Américas.

García Ramírez, Sergio (1976), Los derechos humanos y el Derecho penal, México, Secretaría de Educación Pública. 
Maine, Henry (2001), El Derecho antiguo, traducción de Pastora Rodríguez Aviñoá, México, Editorial Campo Raso.

Nuñez Ávalos, Daniel (2008), El concurso aparente de normas penales, México, Editorial Porrúa.

Pavón Vasconcelos, Francisco (2008), Concurso aparente de normas, séptima edición, México, Editorial Porrúa.

Rodríguez Manzanera, Luis (2015), Penología, séptima edición, México, Editorial Porrúa.

Roxin, Claus (2005), ¿Puede llegar a justificarse la tortura?, México, Instituto Nacional de Ciencias Penales, colección Conferencias Magistrales, número 12.

(1997), Derecho Penal. Parte General Tomo I Fundamentos. La estructura de la teoría del Delito, traducción de la segunda edición alemana de Diego-Manuel Luzón Peña, Miguel Díaz y García Conlledo y Javier de Vicente Remesal, Madrid, Editorial Thomson Civitas.

Ruiz Torres, Humberto Enrique (2007), Curso general de amparo, México, Oxford University Press, colección Textos jurídicos universitarios.

Silva Silva, Jorge A. (1995), Derecho procesal penal, segunda edición, México, Oxford University Press, colección Textos jurídicos universitarios

Savigny, Friedrich Karl von (2004), Sistema del Derecho romano actual, edición facsimilar de la 1879, México, Suprema Corte de Justicia de la Nación, Tomo II.

Steiner, Christian y Uribe, Patricia (2015 coord.), Convención Americana sobre Derechos Humanos comentada, México, Suprema Corte de Justicia de la Nación, Konrad Adenauer Stiftung.

Valadez Díaz, Manuel et al (2011), Diccionario práctico del juicio oral, México, Ubijus.

Zaffaroni, Raúl et al (2005), Derecho penal. Parte general, segunda edición, México, Editorial Porrúa.

Zaffaroni, Eugenio Raúl (2006), El enemigo en el Derecho penal, Buenos Aires, Ediar.

Zamora-Pierce, Jesús (2003), Garantías y proceso penal, doceava edición, México, Editorial Porrúa.

\section{Documentos en línea:}

La tortura en México: una mirada desde los organismos del Sistema de Naciones Unidas, México, Comisión Nacional de Derechos Humanos, Oficina en México del Alto Comisionado de Naciones Unidas para los Derechos Humanos, 2015, [en línea], disponible en: http://appweb.cndh.org.mx/biblioteca/archivos/pdfs/lib_TorturaMexicoUnaMirada. pdf, [consultada el 15 de mayo de 2018]. 
Trump apoya la tortura en los interrogatorios como método efectivo para combatir el terrorismo, El Mundo, 27 de enero de 2017, [en línea], disponible en: http://www.elmundo.es/intern acional/2017/01/26/58896262e5fdeaad368b465f.html, [consultada el 15 de mayo de 2018]. 